\title{
ABORDAGEM COMUNICATIVA: ELO ENTRE O LIVRO “BEM-VINDO!” E O EXAME CELPE-BRAS
}

\author{
COMMUNICATIVE APPROACH: LINK BETWEEN THE TEXTBOOK \\ "WELCOME" AND THE CELPE-BRAS EXAM
}

José Wellisten Abreu de Souza ${ }^{1}$ Gesilândia Evelyn de Oliveira Melo²

\section{RESUMO}

O Ensino de PLE vem sendo uma temática em ascensão. Com o objetivo de ratificar a presença da Abordagem Comunicativa dentro do Exame Celpe-Bras e detectar a presença dessa perspectiva no Livro Didático “Bem-vindo! é que analisamos estes materiais. Além disso, também sugerimos propostas de potencialização para as atividades. Para tanto, valemo-nos da leitura aos trabalhos de Almeida Filho (2013), Geraldi (1997) e Larsen-Freeman (1986). Metodologicamente, partimos de uma pesquisa qualitativa, que nos proporciona uma análise comparativa entre o esperado no Exame e o apresentado pelo LD. Foram definidos na nossa análise os seguintes critérios: atividades "não CELPE", "quase CELPE" e "CELPE". Por fim, confirmamos a presença da Abordagem Comunicativa nos materiais utilizados, observando a progressão dos níveis dentro dos materiais e verificamos a importância do professor como potencializador dos recursos didáticos, quanto à intercessão entre o PLE e o Português LM, promovidas pela necessária reflexão.

\section{Palavras-Chave}

Exame Celpe-Bras. Livro Didático “Bem-vindo!”. PLE. Abordagem Comunicativa.

\begin{abstract}
PLE Teaching has been a growing theme. In order to ratify the presence of the Communicative Approach within the Celpe-Bras Exam and detect the presence of this perspective in the textbook "Welcome!" is that we analyze these materials. In addition, we also suggest enhancement proposals for the activities. To this end, we use the works of Almeida Filho (2013), Geraldi (1997) and Larsen-Freeman (1986). Methodologically, we start from a qualitative research, which provides us with a comparative analysis between the expected in the Exam and the presented by the $L D$. The following criteria were defined in our analysis: "non-CELPE", "quasi CELPE" and "CELPE" activities. Finally, we confirm the presence of the Communicative Approach in the materials used, observing the progression of the levels within the materials and verify the importance of the teacher as a role of enhancing the didactic resources, regarding the intercession between PLE and Portuguese LM, promoted by the necessary reflection.
\end{abstract}

\section{KeYwORDS}

Celpe-Bras exam. Textbook "Welcome!". PLE Communicative Approach.

1 Doutor em Linguística pela Universidade Federal da Paraíba e professor dessa mesma Instituição Federal de Ensino.

2 Graduanda em Letras - Língua Portuguesa pela Universidade Federal da Paraíba. 


\section{CONSIDERAÇÕES INICIAIS}

O ensino da Língua Portuguesa como língua estrangeira é um ensino relativamente novo, que veio ganhando maior destaque e estruturação a partir da década de 70. Ademais, a Língua portuguesa vem ganhando uma maior ascensão no contexto de pluralismo linguístico, sendo assim, devido a programas de incentivo profissional e estudantil, o Brasil desperta o interesse exterior para o aprendizado da língua.

A mencionada questão da ascensão pode ser demonstrada por meio de programas para o incentivo ao ingresso de estudantes internacionais no país, o que também evidencia o incentivo ao pluralismo cultural. Nesse contexto, é válido mencionar o Programa Estudante Convênio de Graduação (PEC-G), responsável, inclusive, pela própria organização e criação do Certificado de Proficiência em Língua Portuguesa para Estrangeiros (Celpe-Bras), já que, em 1993, o Ministério da Educação (MEC) teve de convocar "uma comissão de especialistas para elaborar um exame de proficiência em língua portuguesa para estrangeiros, para atender às necessidades de seleção de estudantes que participariam" ${ }^{3}$ do programa PEC-G. Tal ação culminou, no ano seguinte, com a criação do certificado, efetivado a partir da Portaria n. ${ }^{\circ}$ 1787, de 26 de dezembro de 1994, do MEC, que resolve, "Art. 1. Instituir Certificado de Proficiência em Língua Portuguesa CELPE-BRAS"4.

Assim sendo, o PEC-G “oferece oportunidades de formação superior a cidadãos de países em desenvolvimento com os quais o Brasil mantém acordos educacionais e culturais. [O programa é] desenvolvido pelos ministérios das Relações Exteriores e da Educação, em parceria com universidades públicas - federais e estaduais - e particulares" ". Como requisitos, os estudantes precisam ter entre 18 e 23 anos, ter certificado de conclusão da educação básica ou curso equivalente ao ensino médio brasileiro. Após o processo de seleção, o aluno cursa de forma gratuita o ensino superior, entretanto, precisa ser capaz de custear os seus gastos no país, como também provar proficiência em Língua Portuguesa (por meio do Celpe-Bras). Posteriormente à conclusão do curso de graduação, os alunos devem retornar a seus países de origem para utilizarem dos conhecimentos adquiridos, visando ao desenvolvimento do seu país.

É importante ressaltar que a Universidade Federal da Paraíba (UFPB) recebe estudantes do PEC-G, assumindo também a tarefa de ensinar português aos alunos que fazem parte do programa e que se submeterão ao Exame Celpe-Bras. Nesse contexto, o Programa Linguístico-cultural para Estudantes Internacionais (PLEI) merece destaque: fundado em 1998, vinculado ao maior Centro da UFPB, o Centro de Ciências Humanas, Letras e Artes (CCHLA), o PLEI pertence à Coordenação do Curso de Letras, estando vinculado ao Departamento de Língua Portuguesa e Linguística (DLPL). O Programa PLEI “destina-se a aprofundar os conhecimentos sobre o processo ensino/ aprendizagem do português língua estrangeira (PLE), atuando nas áreas de ensino, pesquisa e extensão"”.

3 Informações retiradas da seção Histórico do Celpe-Bras, presente no site do Instituto Nacional de Estudos e Pesquisas Educacionais Anísio Teixeira (INEP), disponível em: http://bit.ly/2NnkuCh. Acesso em 26 ago. 2019.

4 Portaria n. 1787 , de 26 de dezembro de 1994, publicada no DOU de 02 de jan. de 1995, pág. 39. Disponível em: http://bit. ly/2Nlj4IE. Acesso em 26 ago. 2019.

5 Informações retiradas do portal do Ministério da Educação relativas à seção Apresentação do Programa Estudante Convênio de Graduação (PEC-G), disponível em: http://bit.ly/3afjSbU. Acesso em 26 ago. 2019.

6 Informações retiradas da seção Apresentação do site do Programa Linguístico-cultural para Estudantes Internacionais (PLEI), disponível em: http://bit.ly/2FKbanN. Acesso em 26 ago. 2019. 
Dentro de suas atividades mais específicas, o PLEI promove Cursos de Português como língua estrangeira, tanto para alunos Intercambistas vinculados à UFPB, como também para estudantes conveniados ao PEC-G e para estrangeiros residentes no Brasil. Além disto, promove atividades interculturais, elabora materiais didáticos para os cursos promovidos, desenvolve pesquisas relacionadas ao processo de ensino/aprendizagem de PLE, partindo das questões da identidade e da cultura brasileira. Ademais, é responsável pela aplicação do Certificado de Proficiência em Língua Portuguesa para Estrangeiros (Celpe-Bras).

Uma das importantes contribuições que o PLEI tem promovido desde o início de suas atividades se aplica mais diretamente à formação dos alunos graduandos que atuam no programa. A esse respeito, como relato pessoal, é válido enfatizar a minha atuação no PLEI, no qual participei ativamente durante um ano e oito meses, perpassando por todos os objetivos do programa, ministrando aulas nos níveis, básico e pré-intermediário, que são direcionados para os alunos que têm convênio com a UFPB, os estrangeiros residentes no país e os vinculados ao PEC-G, além disto, participei da elaboração/execução das atividades interculturais, produzindo trabalhos para a apresentação em congressos, participando, ainda, do curso de capacitação do Celpe-Bras e da aplicação deste exame. Além disso, tive contato direto com o Livro Didático "Bem-vindo!", pois como mencionado anteriormente, é o livro adotado pelo Programa. Essa consecução de fatores e vivências nos impulsionou à configuração da proposta deste trabalho.

Sendo assim, após verificar, a presença da Abordagem Comunicativa, ao longo deste processo, na metodologia de ensino, buscamos detectar a Abordagem comunicativa dentro do material didático, sendo assim, o presente trabalho tem como objetivo, analisar a adequação prático-metodológica, desta teoria, no Exame, como também no LD, mas, para além disto, sugerir possíveis formas de aplicação em sala de aula de PLE.

Do ponto de vista metodológico, esta pesquisa assume viés qualitativo. Além disto, buscamos associar a Abordagem Comunicativa com os nossos objetos de estudo, o Exame e o LD, sendo assim, partimos não só da Abordagem, com Larsen-Freeman (1986) e Almeida Filho (2013), mas de autores que trabalham com o ensino de Língua Portuguesa, tais como, Geraldi (1997), como também autores que trabalham com gêneros, tais como Marcuschi (2008). Com Geraldi, especificamente, verifica-se a importância da reflexão permitida pelo trabalho equilibrado entre metalinguagem e eplinguagem.

Após as nossas considerações iniciais, partiremos para as próximas seções, que estão assim organizadas: primeiramente, apresentaremos a Abordagem Comunicativa. Para tanto, organizamos uma breve apresentação histórica e, por seguinte, as principais características que norteiam esta abordagem. Depois disso, buscamos, na seção 3, analisar o elo existente entre o Exame Celpe-Bras, o livro "Bem-Vindo!" e a Abordagem Comunicativa. Na primeira parte, fizemos uma contextualização do Exame, apresentamos os critérios avaliativos, como também, apresentamos uma atividade e um elemento provocador. Vale ressaltar, que a apresentação é de apenas um modelo, pois, podemos observar o padrão mantido pela prova. Sendo assim, tratamos de forma ilustrativa, elencando dois exemplos, que poderiam ser substituídos, pois, os tópicos destacados são comuns para estas Tarefas, frequentes no Exame como um todo. 
Posteriormente, na segunda parte da seção 3, analisamos o LD "Bem-vindo!" à luz da Abordagem Comunicativa. Para tanto, apresentamos a estrutura organizacional do Livro, por seguinte, apresentamos os critérios classificatórios das questões e para finalização, analisamos 4 questões, que classificamos dentro da frequência em que aparecem, pois, assim, como o Exame, o LD apresenta temas similares e propostas de atividades semelhantes. Vale ressaltar, que analisamos o LD como um todo, mas optamos por descrever a análise apenas de uma questão de cada grupo, pertencentes às seções que se repetiam para todos os grupos. Além disto, após a análise, sugerimos possíveis processos de potencialização das atividades, ou seja, refletindo sobre o papel do professor e a importância da escolha das atividades, tópico este destacado como relevante no capítulo da Abordagem Comunicativa.

Como finalização do nosso trabalho, apresentamos uma breve discussão de resultados acerca do nosso questionamento inicial, como também, apresentamos a relevância deste material para docentes de português como língua estrangeira e para nativos, discussão constitutiva de nossas Considerações Finais. Por fim, encontram-se as referências norteadoras da composição deste trabalho.

\section{A Abordagem Comunicativa}

A Abordagem Comunicativa, por sua vez, surgiu em 1970, ainda considerada como uma metodologia recente de estudo. Segundo Martinez (2009), a "Abordagem Nacional-funcional” foi idealizada primeiramente por David Wilkins (1976), emergindo, assim, a partir da necessidade da heterogeneidade do público que buscava ser atendido no ensino de língua. Vale ressaltar que essa abordagem nasce da crítica, como um contra movimento relacionado ao contraste entre língua/ linguagem. Nesse sentido, as principais críticas em torno dos princípios audiolinguísticos se deram por Newmark (1966) e de Newmark e Reibel (1968). Como contra partida destas críticas, Noam Chomsky (1996), em um evento nos Estados Unidos, sugere que existe uma distinção entre uma teoria de língua e uma teoria de aprendizagem de uma (nova) língua, como nos relata Almeida Filho (2001).

De forma mais estrutural, podemos afirmar que desde o começo do século XIX, começaram a surgir algumas das ideias filosóficas base de apoio às novas diretrizes metodológicas, provenientes do pensamento de Hegel, na Alemanha, que tinha prescrito a natureza social do conhecimento produzido em mentes igualmente sociais. A partir de 1967, é válido considerar as contribuições de Dell Hymes, principalmente, com a apresentação do conceito de Competência Comunicativa, inspirado em Roman Jakobson, referente às funções da linguagem. Vale destacar também os estudos sobre Atos de fala, de Austin, na Inglaterra. Sendo assim, a partir da junção do conjunto de ideias e conceitos em relação ao que é língua, sobre aprender e ensinar língua surgiu a Abordagem Comunicativa.

A chegada dessa abordagem ao Brasil ocorre posteriormente, sendo um dos grandes teóricos de referência sobre a abordagem comunicativa Almeida Filho (2013), que sintetiza as teorias de Anthony (1963) e Richards e Rodgers (1986). Para Almeida Filho (2013, p. 30), “[...] uma abordagem equivale a um conjunto de disposições, conhecimentos, crenças, pressupostos e eventualmente princípios sobre o que é a linguagem humana, LE, e o que é aprender e ensinar uma língua alvo (que orienta o processo de ensino aprendizagem)". Logo, inferimos que, a Abordagem Comunicativa trata-se de uma abordagem mais ampla e flexível, pois considera o ensino-aprendizagem a 
partir das crenças, pressupostos e princípios que levam em consideração o contexto e o público alvo. Sendo assim, o aluno aprende a língua a partir do seu uso, na comunicação.

Partindo destas breves definições, inferimos que para o processo de ensino da abordagem comunicativa, se faz necessário que sejam levados em consideração, o processo de decodificação dos signos linguísticos, mas para além disto, as situações reais de uso, pois, a língua não está registrada apenas em seus códigos, mas no processo de interação entre interlocutores e enunciadores, contextos de fala, associados principalmente à finalidade comunicativa presente na escolha e à utilização de determinados códigos.

Alguns dos princípios norteadores da abordagem comunicativa advêm dos trabalhos de Larsen-Freeman (1986) e Almeida Filho (2013), que direcionam quais fatores devem ser priorizados, para que não sejam postos em ênfase só os fatores linguísticos, mas a intenção de promover a competência comunicativa. Vejamos na Tabela 1, a seguir,

Tabela 1: Princípios Norteadores da Abordagem Comunicativa

1. priorização, nos planejamentos, dos aspectos semânticos (e discursivos) da língua alvo, e não dos aspectos gramaticais;

2. ensino da gramática em nível discursivo e pragmático;

3. desenvolvimento das 4 habilidades, de forma integrada, desde o início do processo de ensino e aprendizagem;

4. promoção de compreensão intercultural;

5. envolvimento do aluno na interação em língua-alvo por meio do desenvolvimento de atividades (ou tarefas) comunicativas em pares ou em grupos, com foco na resolução de problemas;

6. avaliação da proficiência por meio de unidades discursivas reais que o aprendiz pode, de fato, realizar.

$$
\text { Fonte: ABRAHÃO, 2015, p. } 27 \text { (adaptado) }
$$

O primeiro ponto desta Abordagem, segundo a tabela acima, nos apresenta a importância do professor, demonstrando que se faz necessária uma organização/preparação por parte deste sujeito no processo ensino-aprendizagem. Isso para muitos pode representar sair de sua zona de conforto, visto que as atividades mecanicistas parecem ser mais cômodas para o professor, requerendo menos esforço para elaboração, dada a cultura da supervalorização da norma, por essas atividades serem de fácil acesso. Sendo assim, o primeiro ponto, trata-se da mudança de recursos utilizados, de modo que não mais se privilegiem atividades mecânicas, puramente morfossintáticas, mas que seja evidenciado o acréscimo da semântica (por meio de atividades/questões/ações metodológicas que busquem explorar os efeitos de sentidos de recursos linguísticos, promovendo melhor compreensão dos textos) e até mesmo da pragmática (por meio de atividades/questões/ações metodológicas que considerem os contextos sociais e culturais envolvidos na língua alvo).

No segundo ponto, ocorre um reforço em relação aos conteúdos que devem ser trabalhados, ou seja, no primeiro momento, a mudança de paradigma da temática e o reforço dado à gramática (que será sim trabalhada), entretanto, não por formas mecânicas, mas de forma reflexiva. Esse ponto já nos leva a refletir sobre o terceiro, quando se verifica menção às quatro habilidades: ler, escrever, compreender e falar, as quais devem ser o foco de desempenho dos alunos. Sendo assim, com a nossa análise, poderemos verificar que tanto na categorização das atividades do LD, como nos níveis do Exame, estas habilidades estarão presentes. 
Os três últimos pontos tratam, respectivamente, do aspecto intercultural, do envolvimento do aluno e dos métodos avaliativos, No primeiro caso, como veremos no Exame Celpe-Bras, mais explicitamente em sua parte oral, trabalha-se com questões que fazem associação com o país do aluno, trazer o assunto de maior domínio do aluno, sua cultura, como ponto de partida para as atividades. Nesse sentido, em uma das atividades que analisamos, também observamos a valorização da cultura do aluno. Por consequência, inferimos que, com a adoção dessa prática, os alunos serão envolvidos diretamente nas atividades. Tal propositura, nos leva a atender o proposto no quinto ponto, cujas atividades serão baseadas no uso real da língua, o que reforça a importância da utilização de materiais autênticos. Por fim, mas não menos importante, os métodos avaliativos devem ser elaborados como um processo e não tendo como objetivo central gerar um produto, valendo acrescentar a importância que as propostas da reescrita/refacção assumem nesse processo.

Logo, a Abordagem Comunicativa pode ser vista como uma metodologia cuja característica é pôr o aluno em confronto com a língua alvo, seja na modalidade oral e/ou escrita, seja por meio da leitura e/ou produção de textos em gêneros variados. A partir deste contato direto com a língua alvo o estudante será capaz de atingir as quatro habilidades - escuta, leitura, fala e escrita. Com base no exposto, parece ser válido discutir, brevemente, alguns aspectos sobre o universo dos gêneros textuais.

Marcuschi (2008) sugere que o trabalho com gêneros não é algo novo, posto que surgiu no Ocidente há mais ou menos vinte e cinco séculos, levando em consideração que sua forma sistemática se iniciou com Platão. Mas, a partir do século XX, ocorreu uma explosão de estudos entorno da temática.

Ainda dentro deste percurso histórico, uma proposta de esquematização dos gêneros, conforme Marcuschi, remonta a Aristóteles, que no capitulo três da Retórica apresenta três elementos que atuam na composição de um gênero: aquele que fala, aquilo sobre o que se fala e aquele a quem se fala. O autor ainda indica que é com Bakhtin que a questão sobre gêneros textuais passa a considerar a língua como um processo de interação, de modo que o texto revela plenamente a língua no âmbito da forma, mas também do discurso.

Partindo desta concepção de gênero, já podemos fazer uma associação direta com o que veremos nos próximos capítulos, quando falaremos sobre a construção dos enunciados do Exame Celpe-Bras, e dos comandos que são dados dentro dos enunciados do LD “Bem-Vindo!".

Sendo assim, inferimos que o trabalho com gêneros em sala de aula leva o aluno a adaptar-se a diferentes situações, logo, espera-se que o aluno reflita sobre o uso da língua, ou seja, podemos ligar diretamente a proposta do Exame e do LD, nas quais o aluno/candidato deve ser capaz de dominar a língua a partir do uso.

Ainda nesta questão de gêneros em sala de aula, Scheneuwly e Dolz (2004) acrescentam que é importante trabalhar com os gêneros orais em sala de aula. Ao falar dos gêneros em geral, o autor, fala sobre a apropriação do gênero, que se trata do processo de internalização do conhecimento. Sendo assim, a partir do que vimos no decorrer dos estudos acerca dos gêneros, inferimos que a utilização dos gêneros orais e escritos em sala de aula serve como fio condutor para todos os processos de aprendizagem. Assim, parte-se do gênero (inclusive considerando questões sobre sua estrutura composicional) esperando que o aluno seja capaz de refletir sobre questões externas que 
influenciam neste processo e, por fim, ocorre o processo de internalização, ou seja, o aluno não só entende, mas é capaz de aplicar.

Por fim, para fundamentação de nossa análise, trabalhamos com as concepções de Geraldi (1997) sobre o ensino Metalinguístico e o Epilinguístico. Segundo o autor, as atividades de reflexão sobre a língua se diferenciam nos seus fins. Nas atividades epilinguísticas, a reflexão está voltada para o uso, no próprio interior da atividade linguística em que se realiza. Já as atividades metalinguísticas estão relacionadas a um tipo de análise voltada para a descrição, por meio da categorização e sistematização dos elementos linguísticos.

Vejamos a seguir, qual a concepção de Geraldi (1997) quando explica a natureza das atividades metalinguísticas,

[...] admitir que nas ações linguística há já ações de reflexão sobre a linguagem. E não poderia deixar de ser assim, ou a linguagem, não seria o que é. Se entendemos a linguagem como mero código, e a compreensão como decodificação mecânica, a reflexão pode ser dispensada (GERALDI, 1997, p. 18).

Sendo assim, quando falamos de metalinguagem, estamos falando de processos de decodificação, o qual, apresentar de produzir aprendizado, não é ainda suficiente para o desenvolvimento da reflexão significativa acerca do texto, como veremos posteriormente no capítulo "Abordagem Comunicativa e o LD "Bem-vindo!".

Vejamos agora, como Geraldi (1997) apresenta a noção de Epilinguaguem,

[...] conjunto de atividades que tomam uma das características da linguagem como seu objeto: o fato de ela poder remeter a si própria, ou seja, como a linguagem não só falamos sobre o mundo ou sobre nossa relação com as coisas, mas também falamos sobre como falamos. (GERALDI,1997, pp. 189-190).

Sendo assim, observamos que é acrescido o papel da reflexão no processo ensino-aprendizagem. Assim, o autor reafirma que o processo reflexivo não é só externo, mas levar o aluno a refletir sobre a própria língua, tornando assim, a aprendizagem significativa.

Em suma, quando falamos sobre Metalinguagem, estamos fazendo referência ao ensino da língua pela língua, ou seja, conhecer as questões mais gramaticais e suas funções. Já quando fazemos referência ao ensino Epilinguístico, estamos falando de um trabalho não apenas estrutural, mas reflexivo, ou seja, o aluno não é direcionado para preencher lacunas, mas este mecanismo de preenchimento recebe como acréscimo a reflexão sobre os fatores que interferem na língua.

Essa nos parece uma associação bastante possível, portanto, traçar metas que instrumentalizem nossos alunos por meio de conhecimentos linguísticos, tendo por foco a língua em seus reais contextos de uso, configura-se como o caminho mais seguro para que haja um real desenvolvimento dos alunos estudantes de PLE.

Sendo assim, associando ao nosso material de análise, o LD, percebemos que o mesmo leva o aluno a uma progressão, como confirmaremos na nossa análise, mas, inferimos também, que o Exame certifica aqueles que são capazes de entenderem os enunciados epilinguísticos, usando como pressuposto, a compreensão dos gêneros, logo atendendo aos critérios da Abordagem Comunicativa. 
Com base no exposto, buscaremos observar o funcionamento da Abordagem Comunicativa no Exame Celpe-Bras, como também no Livro Didático “Bem-Vindo!”, com o objetivo de analisar a adequação prático-metodológica desta teoria, visando, além disto sugerir possíveis formas de aplicação em sala de aula de PLE.

\section{Abordagem comunicativa: exame Celpe-Bras e o LD “Bem-vindo!"}

A composição desta seção considera dois momentos: de forma inicial, conheceremos o Exame Celpe-Bras, tanto a sua contextualização, como também a forma como se estrutura, além disso, quais critérios compõem seus níveis de certificação. Por seguinte, apresentaremos o LD "Bem-Vindo!", inicialmente sua organização estrutural, partindo para uma análise de quatro questões selecionadas como exemplos prototípicos do que ocorre com frequência dentro do material. Vale ressaltar que os critérios classificatórios para o Exame e para as atividades tem como embasamento teórico a Abordagem Comunicativa, mas como acréscimo, buscamos associar aos trabalhos relacionados com a utilização dos gêneros textuais e as questões sobre reflexão da língua, atribuindo, por fim, possíveis papeis para o professor.

\section{A Abordagem comunicativa e o exame Celpe-Bras}

O Certificado de Proficiência em Língua Portuguesa (Celpe-Bras) é o exame oficial de certificação, mais precisamente (cf. Manual do examinando, 2015, p. 8), o único que é reconhecido internacionalmente, como o meio de certificação do português como língua estrangeira.

O exame Celpe-Bras começou a ser aplicado com a responsabilidade do (INEP) em outubro de 1998 e desde 1999 vem sendo aplicado duas vezes ao ano, exceto em 2018, que ocorreu apenas uma edição do exame. As provas são aplicadas tanto em nível nacional, como também para os estrangeiros que, mesmo não morando no Brasil, desejam obter esta certificação. Para a aplicação da prova, existe uma rede de postos aplicadores que, de forma majoritária, encontram-se nas instituições de nível superior, valendo mencionar inclusive, a Universidade Federal da Paraíba (UFPB) como um destes postos aplicadores.

O exame também é porta de entrada para os estudantes internacionais que desejam ingressar nas universidades brasileiras da rede pública, seja em nível de graduação, seja em nível de pós-graduação, funcionando, nesse último caso, como exame de proficiência à semelhança de outros testes aplicados, por exemplo, pela/o British Council, Instituto Cervantes, Aliança Francesa e Goethe Institut, tais como TOEFL, IELTS e exames de proficiência de Cambridge, para a comprovação de proficiência em língua inglesa, DELE e SIELE, certificados/diplomas que avaliam as competências em língua espanhola, DELF e DALF, diplomas oficiais referentes ao reconhecimento da proficiência em língua francesa, e o Goethe-Zertifikat, que comprova a competência em alemão ${ }^{7}$.

Além disso, o Celpe-Bras passou a ser exigido como documento para validação de diplomas, por meio do qual o estrangeiro pode conseguir visto permanente e, assim, continuar residindo no Brasil. Por fim, é também usado como critério por algumas instituições para que o estrangeiro consiga ingressar no mercado de trabalho. Vale ressaltar também que para realização da prova o candidato(a) precisa ter acima de 16 anos e o equivalente ao nível fundamental brasileiro.

7 As informações reunidas acerca dos principais exames de proficiência foram retiradas do seguinte endereço eletrônico: http:// bit.ly/2RgbuAh. Acesso em 17 jun. 2019. 
Quando falamos na questão de concepção teórica o exame avalia a língua a partir do seu uso, sendo assim, parte-se de uma concepção que para que o candidato/estrangeiro receba o certificado de domínio da língua se faz necessária às adequações as diferentes situações. Então, ele precisa ser capaz de a partir de situações reais de uso, compreender a temática, assumir um papel social, desenvolver uma produção oral ou escrita. Um dos grandes diferencias do exame é que ele fornece a mesma avaliação para todos os candidatos e, a partir do desempenho, ocorre o processo de certificação.

No Quadro 1 a seguir, buscamos esquematizar de forma didática os níveis de certificação e os critérios para o alcance de cada nível, valendo ressaltar que para que receba certificado no Exame, se faz necessário alcançar o nível Intermediário. Logo, mesmo que para o exame qualquer pessoa seja capaz de desempenhar ações da Língua Portuguesa, existe critérios básicos para receber o certificado, aqueles que não conseguem alcançar este nível, são categorizados como "Sem certificação", vejamos:

Quadro 1- Níveis de certificação, os seus critérios e os desvios permitidos

\begin{tabular}{|c|c|c|}
\hline Nível de certificação & Critérios & Desvios \\
\hline Intermediário & $\begin{array}{l}\text { Fornecido para o candidato que } \\
\text { apresentou domínio operacional } \\
\text { parcial da Língua Portuguesa, sendo } \\
\text { capaz de produzir e compreender } \\
\text { textos orais e/ou escritos sobre } \\
\text { assuntos limitados, contextos } \\
\text { conhecidos e situações do cotidiano. }\end{array}$ & $\begin{array}{l}\text { Para este nível é permitido que } \\
\text { ocorra inferências de ouras línguas } \\
\text { estrangeiras, ou de sua língua } \\
\text { materna, mas de forma que não } \\
\text { ocorra o comprometimento da } \\
\text { comunicação. }\end{array}$ \\
\hline Intermediário Superior & $\begin{array}{l}\text { Conferido ao candidato o } \\
\text { atendimento as mesmas } \\
\text { características do nível anterior } \\
\text { buscando cada vez mais clareza nas } \\
\text { informações. }\end{array}$ & $\begin{array}{l}\text { Neste nível a frequência das marcas } \\
\text { de outras línguas deve ser menor do } \\
\text { que a do nível anterior. }\end{array}$ \\
\hline Avançado & $\begin{array}{l}\text { Fornecido ao candidato que } \\
\text { apresentou o domínio amplo da } \\
\text { Língua Portuguesa que demonstre } \\
\text { ser capaz de produzir textos orais } \\
\text { e/ou escritos sobre assuntos } \\
\text { variados em contextos conhecidos e } \\
\text { desconhecidos. }\end{array}$ & $\begin{array}{l}\text { Para este nível são permitidas } \\
\text { inadequações ocasionais na } \\
\text { comunicação, principalmente } \\
\text { em contextos desconhecidos, } \\
\text { mas de forma que não ocorra o } \\
\text { comprometimento da comunicação. }\end{array}$ \\
\hline Avançado Superior & $\begin{array}{l}\text { Conferido ao candidato que } \\
\text { preencha todos os quesitos do nível } \\
\text { Avançado. }\end{array}$ & $\begin{array}{l}\text { Neste Nível pode ocorrer } \\
\text { intervenções de outras línguas, mas } \\
\text { de forma ainda menos do que no } \\
\text { nível anterior. }\end{array}$ \\
\hline
\end{tabular}

Como podemos ver no Quadro 1, tanto a explicação dos critérios como dos desvios podem ser assemelhados ao exposto anteriormente no que se refere às características da abordagem comunicativa, na medida em que um dos requisitos é a busca por alcançar a comunicação, atendendo aos objetivos estabelecidos pelo enunciado do exame, como veremos no exemplo indicado na Figura 1 , analisado posteriormente no decorrer deste capítulo.

Segundo o Manual do Examinando (2015), verifica-se uma hierarquia no desempenho das ações que o candidato é capaz de mobilizar em Língua Portuguesa, ou seja, do nível "Sem Certificação", o candidato apresenta fortes marcas da sua língua materna, não sendo capaz de desenvolver 
um argumento com tanta clareza, demonstrando, ainda, reincidência em desvios da norma padrão, até o nível "Avançado Superior", quando o candidato é plenamente capaz de se adequar a diferentes situações, não cometendo desvios da norma padrão e não apresentando marcas da língua materna, demonstrando competência para entender e produzir as atividades propostas pelo exame.

Ainda segundo este manual, o Exame apresenta três características principais: a ênfase no uso da língua, a utilização de textos autênticos e a avaliação integrada de compreensão e da produção, tanto oral quanto escrita. A primeira destas características faz referência ao já exposto anteriormente, que é reforçado quando falamos que o Exame apresenta uma abordagem comunicativa, já a segunda característica faz referência ao fato de que todos os materiais usados na prova são divulgados no meio midiático, sendo, segundo Isolla (2014), em grande parte gêneros do meio jornalístico, pois acredita-se que é o maior meio de contato que o estrangeiro tem com a língua e, por fim, a terceira característica que diz respeito ao fato de a mesma prova ser utilizada para diferentes níveis de certificação.

No que se refere a sua estrutura, o exame é dividido em duas grandes partes: a Parte Escrita e a Parte Oral. A primeira parte é aplicada de forma coletiva, majoritariamente no primeiro dia, no tuno da manhã, não podendo ser modificado o horário pelo posto aplicador, a duração é de apenas 3 horas de prova, a qual é composta por quatro tarefas que visam diferentes competências, vejamos a seguir no Quadro 2 como se organiza a parte escrita do exame:

\begin{tabular}{|l|l|l|}
\hline \multicolumn{2}{|c|}{ Quadro 2- Parte escrita do Celpe-BRAS } \\
\hline 1 & \multicolumn{1}{|c|}{ TEXTO BASE } & \multicolumn{1}{c|}{ HABILIDADES AVALIADAS } \\
\hline 2 & Vídeo & Compreensão oral e escrita, como também produção escrita; \\
\hline 3 & Áudio & Compreensão oral e escrita, como também produção escrita; \\
\hline 4 & Texto escrito & Compreensão escrita e produção escrita; \\
\hline \multicolumn{2}{|c|}{ Fonte: Manual do Examinando (2015, p. 17) (adaptado). }
\end{tabular}

Em cada uma das tarefas, será necessário que o candidato seja capaz de compreender o texto base apresentado, seja ele oral e/ou escrito, como também ser capaz de filtrar as informações que julgar relevantes para a produção que posteriormente será desenvolvida. Além disso, o participante precisa colocar-se em determinado papel social, ou seja, ao ler a questão o participante terá que identificar em qual cargo social ele deve se posicionar, por exemplo, ser Gerente de recursos humanos, por seguinte, será necessário que o participante identifique qual a pessoa ou grupo específico ao qual ele precisa se direcionar, como por exemplo, o diretor da sua empresa, por fim, será o momento de identificar o gênero e o propósito comunicativo, como por exemplo, um e-mail, com o objetivo de convencer a ideia apresentada pela reportagem, "Meu escritório em casa" poderia ser implementada na empresa, como podemos ver na edição, 2016/2, atividade 3. 
Figura 1: Tarefa $3(2016 / 2)$



Fonte: Acervo Celpe-Bras, 2016/2.

Assim, como no exemplo acima, o candidato deve identificar dentro do enunciado, uma ordem lógica de enunciador, interlocutor e propósito, para que seja capaz de usar as informações que destacou dos textos base, para construir a produção solicitada pelo enunciado. Vale ressaltar que este enunciado é construído de forma descritiva, ou seja, apresenta uma suposta situação em que o participante estaria, e não de forma objetiva como apresentada anteriormente.

Como vimos anteriormente, quando tratamos do ensino que contempla aspectos estruturais e funcionais da língua, estamos falando de uma perspectiva socio-interativa (MARCUSCHI, 2008) que tem o estudo pautado em gêneros textuais. Sendo assim, verificamos que a proposta prática- 
-metodológica do exame parte do pressuposto da importância interacional do candidato, mesmo que sendo relevante também o domínio da norma culta.

Antes que os candidatos assistam ao vídeo e/ou escutem o áudio, o coordenador responsável pela aplicação da prova solicita a leitura do enunciado, para que nas duas vezes em que se repetem o texto base, eles busquem filtrar as informações relevantes, o que não acontece nas tarefas três e quatro, pois continuam disponíveis para o candidato.

De forma mais objetiva, veremos a composição de cada tarefa, pois, posteriormente, isso nos será necessário para a associação com o material didático analisado. Nesse sentido, a Tarefa 1 é composta por uma parte de um vídeo, com duração aproximada de 3 (três) minutos, e baseia-se em uma proposta de ação que define os três aspectos que citamos anteriormente (enunciador, interlocutor e propósito). Na Tarefa 2, o candidato escutará a um seguimento de áudio, que tem duração média de 3 (três) minutos e que também será texto base para definir os três aspectos já mencionados. Ambas as tarefas serão repetidas duas vezes, ocorrendo um intervalo de 30 minutos entre as tarefas, valendo ressaltar que a compreensão escrita de ambas as atividades é considerada pela compreensão dos enunciados.

Por fim, as Tarefas 3 e 4 são compostas, cada uma, por um texto escrito, que em sua maioria são textos retirados de revistas e ou jornais. A extensão média destes textos é de até uma página, o que para muitos candidatos torna o texto cansativo para ser lido e de difícil compreensão, mesmo que, de modo geral, sejam textos de uma linguagem acessível. Assim como as tarefas anteriores, a partir destes textos-base os candidatos precisam utilizar as informações fornecidas para escreverem o gênero específico, atendendo aos aspectos de enunciador, interlocutor e propósito comunicativo, como vimos no exemplo citado anteriormente (Figura 1), ou seja, de forma objetiva, as quatros tarefas buscam levar o candidato a se posicionar em diferentes situações de fala, simulando o cotidiano.

No que se refere à Parte Oral do Exame, ela consiste em uma Interação Face a Face de 20 (vinte) minutos, no momento da entrevista, que é feita de forma individual, permanecendo na sala apenas o Avaliador Interlocutor (AI) e o Avaliador Observador (AO), entretanto o AO, como o próprio nome sugere, apenas observa a conversa e não pode falar nada durante a entrevista. A entrevista tem como objetivo observar a capacidade do candidato de conversar, de forma mais natural possível, sobre diferentes assuntos da cultura brasileira e da atualidade, principalmente assuntos divulgados no meio midiático.

Vejamos no Quadro 3 a seguir, de forma objetiva, como se dá a composição da segunda parte do exame:

Quadro 3- Parte Oral do CELPE-BRAS

\begin{tabular}{|l|l|l|l|}
\hline Parte & \multicolumn{1}{|c|}{ Conteúdo da Interação } & \multicolumn{1}{c|}{ Habilidades avaliadas } & \multicolumn{1}{c|}{ Tempo } \\
\hline 1 & $\begin{array}{l}\text { Conversa sobre os interesses pessoais } \\
\text { do candidato, a partir das informações } \\
\text { fornecidas no formulário de inscrição. }\end{array}$ & $\begin{array}{l}\text { Compreensão oral e } \\
\text { produção oral }\end{array}$ & 5 minutos \\
\hline 2 & $\begin{array}{l}\text { Conversar sobre tópicos de interesse geral } \\
\text { com base em três Elementos Provocadores }\end{array}$ & $\begin{array}{l}\text { Compreensão oral e } \\
\text { produção oral }\end{array}$ & $\begin{array}{l}15 \text { minutos, sendo estes } \\
\text { divididos } 5 \text { minutos } \\
\text { para cada EP. }\end{array}$ \\
\hline
\end{tabular}

Fonte: Manual do Examinando (2015, p. 20) (adaptado). 
Como vemos no Quadro 3, no momento inicial da conversa ocorre um diálogo mais pessoal, com o objetivo de criar um ambiente favorável e mais descontraído para a interação, após este momento, o candidato recebe os Elementos Provocadores (EP), como vemos abaixo, com o exemplo da Figura 2:

Figura 2: Elemento provocador 8, 2016/1

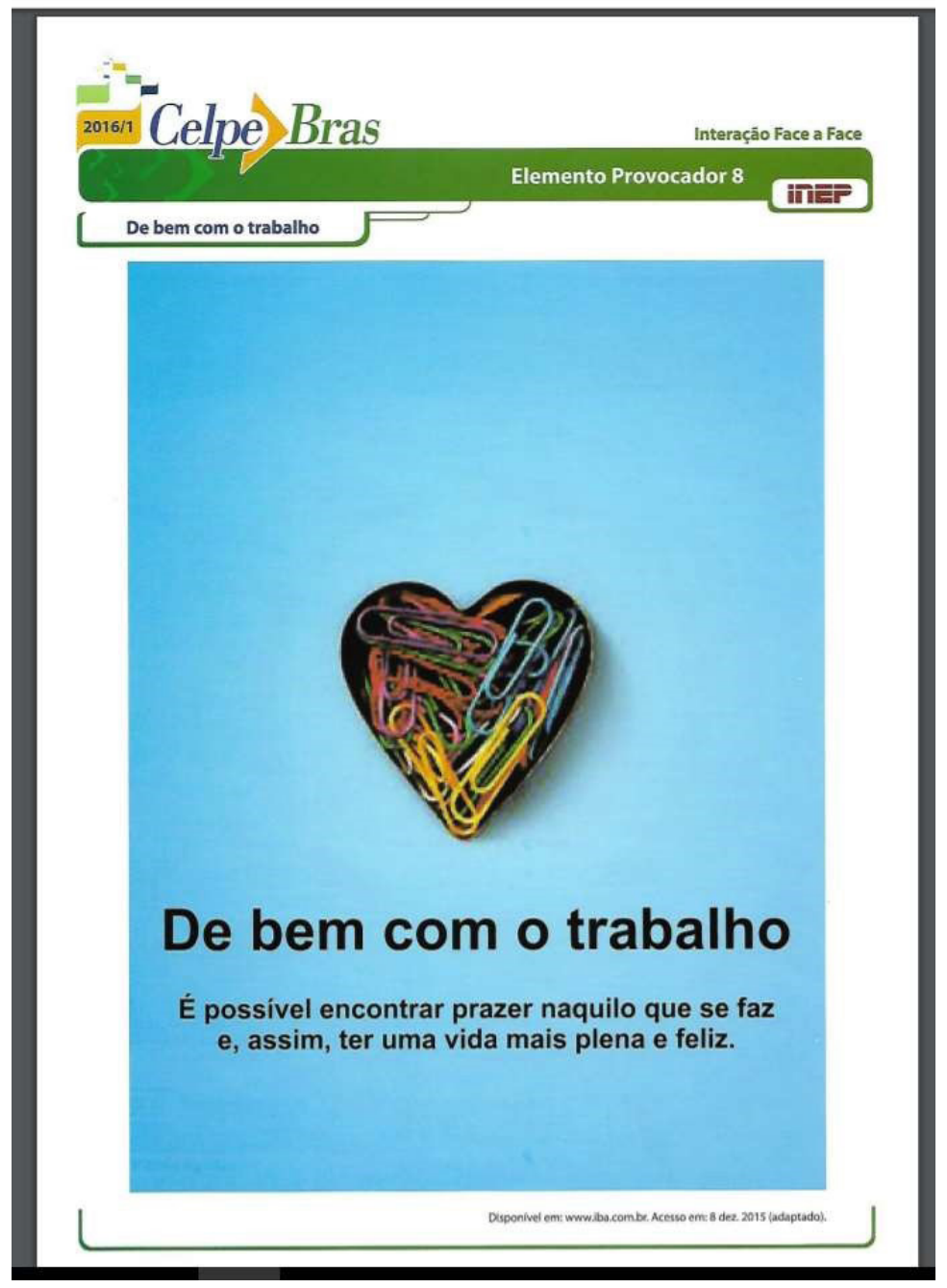

Fonte: Acervo Celpe-Bras, 2016/1.

Os textos-base para a motivação da conversa, usados, portanto, para o momento da avaliação de alguns aspectos comunicativos, recebem maior prioridade, como por exemplo o entendimento da fala do AI, bem como as ideias expressas, seja por meio da linguagem oral ou imagética, apresentadas nos Elementos Provocadores. Nesse sentido, a conversa será guiada pelo AI de forma imparcial, de modo que proporcione maior conforto. Por seguinte, vale ressaltar que a nota geral atribuída ao candidato será a menor, considerando a comparação entre o resultado da prova oral e da escrita, o que de certo modo exclui o desempenho em uma das partes da prova.

Por fim, após o processo de descrição e análise do Exame Celpe-Bras, analisaremos na seção a seguir o material didático "Bem-vindo". Vale ressaltar que a proposta se dá pela importância dos recursos didáticos para o desenvolvimento do aluno/estrangeiro na Língua Portuguesa. 


\section{A ABordagem Comunicativa e o LD "Bem-Vindo!"}

Nesta seção, analisaremos o livro "Bem-Vindo! A língua portuguesa no mundo da comunicação", de Maria Harumi de Ponce, Silva Andrade Burim e Susanna Florissi. Este livro está direcionado ao ensino de português como língua estrangeira, publicado pela editora HUB. Tal obra está na $9^{a}$ edição, a qual foi publicada no ano de 2017, na versão direcionada para o aluno.

No que se refere ao seu formato estrutural, o livro contém 225 páginas, que são divididas em cinco grupos, os quais, podemos inferir, fazem referência a assuntos previstos para serem estudados de acordo com os níveis relativos ao processo de aquisição da língua, a saber: nível básico, nível pré-intermediário, nível intermediário e nível avançado, valendo ressaltar que os dois primeiros grupos fazem referência ao primeiro nível.

No Quadro 4 a seguir, observamos como se dá a organização do livro, que será detalhada partindo dos grupos, por seguinte, seus capítulos, logo após, indicamos as subdivisões, que chamamos de seções e, por fim, as temáticas de cada uma delas, para melhor visualização detalhamos cada um dos grupos, considerando a frequência e/ou repetição das partes mencionadas.

\begin{tabular}{|l|l|l|l|l|}
\hline \multicolumn{5}{|c|}{ Quadro 4: Grupo 1- Eu e Você } \\
\hline Unidades & Prazer em conhecê-lo! & $\begin{array}{l}\text { Meu presente, meu } \\
\text { passado }\end{array}$ & $\begin{array}{l}\text { Meu presente, } \\
\text { meu passado (2) }\end{array}$ & Meu Futuro \\
\hline Seção & APRENDA & APRENDA & APRENDA & APRENDA \\
\hline Seção & ESTUDO DE... & ESTUDO DE... & ESTUDO DE... & ESTUDO DE... \\
\hline Seção & ENFOQUE & ENFOQUE & ENFOQUE & ENFOQUE \\
\hline Seção & PSIU! & PSIU! & PSIU! & PSIU! \\
\hline Seção & GRAMÁTICA & GRAMÁTICA & GRAMÁTICA & GRAMÁTICA \\
\hline
\end{tabular}

A partir do exposto, observamos que a organização do Grupo 1 se dá em quatro unidades, que são divididas em seis sessões, que neste grupo são nomeadas da mesma forma, já no que se refere às temáticas, inicialmente, trabalham-se os temas relacionados ao primeiro contato do estrangeiro com a nova língua, sendo assim, são apresentadas questões básicas como os cumprimentos, alfabeto, dias da semana, chegando na unidade quatro, que trata sobre as formas de pagamento. Acerca deste grupo, as autoras dizem que "Este Grupo (1) apresenta o presente, o passado e o futuro. O objetivo é dar ferramentas para que os alunos possam falar de si mesmos, de suas lembranças, hábitos, rotina, planos e também cumprimentar e conhecer outras pessoas" (PONCE; BURIM; FLORISSI, 2009, p. 9) ${ }^{8}$. Tal consideração comprova que o objetivo destas quatro unidades é trabalhar o momento inicial do estrangeiro no país.

No que se refere ao Grupo 2, ocorre uma divisão semelhante, como veremos a seguir no Quadro 5,

8 As citações de Ponce, Burim e Florissi (2009) foram retiradas do manual do professor, porém de uma versão anterior ao livro didático analisado neste trabalho. Consideramos válido trazer a percepção das autoras, pois podemos compreender como eles concebem que deva ser feito o trabalho com o manual. Apesar de serem manuais de edições diferentes, verificamos poucas alterações entre as edições, mormente detidas em aspectos editoriais do que quanto ao conteúdo e/ou atividades. Assim, para fins de análise consideramos o manual mais recente (2017). 
Quadro 5: Grupo 2- O Brasil e sua língua

\begin{tabular}{|l|l|l|l|l|}
\hline \multicolumn{1}{|c|}{ Unidades } & \multicolumn{1}{|c|}{ Minhas expectativas } & Meus sonhos e desejos & \multicolumn{1}{|c|}{ A chegada } & \multicolumn{1}{|c|}{ O país e o idioma } \\
\hline Seção & APRENDA & APRENDA & APRENDA & APRENDA \\
\hline Seção & ESTUDO DE... & ESTUDO DE... & ESTUDO DE... & ESTUDO DE... \\
\hline Seção & ENFOQUE & ENFOQUE & ENFOQUE & ENFOQUE \\
\hline Seção & PSIU! & PSIU! & PSIU! & PSIU! \\
\hline Seção & GRAMÁTICA & GRAMÁTICA & GRAMÁTICA & GRAMÁTICA \\
\hline
\end{tabular}

Como podemos observar, a nomenclatura das seções são as mesmas do grupo anterior, porém, no que se refere às temáticas, são abordados assuntos como fazer compras até diálogos em restaurantes. Sendo assim, a partir das temáticas, podemos inferir que estes dois grupos estão associados ao momento inicial do processo de aquisição da língua e adaptação no país, que neste momento podemos classificar como um nível básico. Nas palavras das autoras,

\begin{abstract}
Este Grupo apresenta o Brasil e seu idioma, ampliando o conhecimento anteriormente adquirido pelos alunos sobre o país, seus costumes e suas características, bem como sobre a Língua Portuguesa e sobre onde é falada no mundo. Trata também das expectativas dos alunos antes de vir ao Brasil e de sua chegada no país (PONCE; BURIM; FLORISSI, 2009, p. 9).
\end{abstract}

De forma objetiva, constatamos que as oito primeiras unidades, correspondentes ao Grupo 1 e ao Grupo 2, seguem um padrão formado pelo assunto principal, por seguinte, verifica-se a seção nomeada como "Aprenda", seção em que o aluno será apresentado a textos e a explicações sobre o conteúdo da unidade, por seguinte, temos a seção "Estudo de...", na qual verifica-se o assunto gramatical esperado que o aluno domine ao finalizar a unidade. Em seguida, na seção "Enfoque", verificam-se os assuntos com maior destaque dentre aqueles apresentados anteriormente, ou que, para a lógica das autoras, são de maior pertinência neste momento, logo após, vem a seção nomeada como "Psiu!", na qual o aluno é levado a adquirir um pouco mais de vocabulário, voltado ao cotidiano, e, por fim, encontra-se a seção "Gramática", na qual é apresentada uma grade de verbos, ou pontos importantes, dentro das características gramaticais, que os alunos precisam prestar mais atenção.

No Quadro 6, a seguir, veremos como se dá a organização do Grupo 3. Vale destacar que consideramos este grupo referente ao nível Pré-Intermediário, ou seja, a partir de agora, espera-se que o aluno seja capaz de um aprofundamento maior nas funções. Nas palavras das autoras isso confirma, na medida em que sugerem que

Este Grupo destina-se a apresentar o dia a dia no Brasil e as especificidades brasileiras ao se procurar onde morar; a manutenção da residência; o bairro; os sistemas de educação e saúde. A última página de cada Unidade deste grupo contém um texto bastante resumido de nossa História, do Descobrimento até os dias atuais (PONCE; BURIM; FLORISSI, 2009, p. 104).

Quadro 6: Grupo 3- A sociedade e sua organização

\begin{tabular}{|l|l|l|l|l|}
\hline \multicolumn{1}{|c|}{ Unidades } & \multicolumn{1}{|c|}{ O lar } & \multicolumn{1}{c|}{ O bairro } & \multicolumn{1}{c|}{ A educação } & \multicolumn{1}{c|}{ A saúde } \\
\hline Seção & APRENDA & APRENDA & APRENDA & APRENDA \\
\hline Seção & ESTUDO DE... & ESTUDO DE... & ESTUDO DE... & ESTUDO DE... \\
\hline Seção & ENFOQUE & ENFOQUE & ENFOQUE & ENFOQUE \\
\hline Seção & PSIU! & PSIU! & PSIU! & PSIU! \\
\hline Seção & HISTÓRIA (1) & HISTÓRIA (3) & HISTÓRIA (4) \\
\hline
\end{tabular}

Fonte: a própria autora, 2019. 
No Grupo 3, ocorre uma substituição de uma seção, a seção intitulada "Gramática" é retirada, mas ainda está presente de forma diluída nas demais seções, por seguinte, insere-se a seção "História" associada à temática trabalhada na Unidade. Na seção inserida, ocorre um aprofundamento temático, apresentam-se quatro textos que contam como se deu o processo histórico pelo qual o Brasil passou, da época do império, posteriormente República, a Democracia contemporânea e, por fim, fala sobre a estabilidade econômica. Assim sendo, observa-se que nesta seção a grade de verbos é retirada, iniciando-se um processo de leitura de textos mais extensos e com um vocabulário mais específico. Um detalhe que merece destaque é o fato de não ser apresentada uma atividade previamente selecionada, ou seja, o professor irá decidir de que forma abordará estes textos com seus alunos.

Logo após, temos o Grupo 4, grupo este que apresenta diferenças com relação ao descrito nos três grupos anteriores, vejamos a seguir:

Quadro 7: Grupo 4- O trabalho e suas características

\begin{tabular}{|l|l|l|l|l|}
\hline \multicolumn{1}{|c|}{ Unidades } & \multicolumn{1}{|c|}{ Minhas expectativas } & \multicolumn{1}{|c|}{ Meus sonhos e desejos } & \multicolumn{1}{c|}{ A chegada } & \multicolumn{1}{c|}{ O país e o idioma } \\
\hline Seção & APRENDA & APRENDA & APRENDA & APRENDA \\
\hline Seção & ESTUDO DE... & ESTUDO DE... & ESTUDO DE... & ESTUDO DE... \\
\hline Seção & ENFOQUE & ENFOQUE & ENFOQUE & ENFOQUE \\
\hline Seção & PSIU! & PSIU! & PSIU! & PSIU! \\
\hline Seção & AMPLIE SEU & AMPLIE SEU & AMPLIE SEU & AMPLIE SEU \\
& VOCABULÁRIO & VOCABULÁRIO & VOCABULÁRIO & VOCABULÁRIO \\
\hline
\end{tabular}

Podemos observar que ocorre uma progressão expressa pela escolha de novidades, para atender às necessidades correspondentes a cada nível. Como é proposto por Ponce, Burim e Florissi, (2009, p. 152), "este grupo apresenta vocabulário e situações referentes ao ambiente, ao local e ao mercado de trabalho. Fala-se de globalização, de qualidade, de comunicação, enfim, de tudo que se relaciona às empresas modernas".

Classificamos o Grupo 4 como o referencial esperado para o aluno de um Nível Intermediário, pois, a partir das situações e, principalmente, de gêneros mais formais, o aluno será capaz de desenvolver as competências, semelhantemente ao cobrado pelos critérios estabelecidos pelo Exame Celpe-Bras.

Também o Grupo 5 representa um aprofundamento, cuja estruturação revela diferenças quanto aos grupos anteriores. Para as autoras, "este grupo foi dividido em Unidades que tratam do lazer em casa, fora de casa, os esportes, a arte e a música brasileiras. Apresenta ainda informações sobre nossa gente, nossa literatura, e sobre os países onde a língua portuguesa é o idioma oficial" (PONCE; BURIM; FLORISSI, 2009, p. 196).

Logo, inferimos que, neste Grupo, o aluno já é capaz de entender as funções básicas que perpassam os níveis, ou seja, encontra-se em um nível superior (nível avançado), vejamos a sua organização estrutural no Quadro 8: 
Quadro 8: Grupo 5- Diversão-Cultura

\begin{tabular}{|l|l|l|l|l|}
\hline Unidades & Lazer em casa & Saindo de casa & Esportes & Arte- música \\
\hline Seção & CURIOSIDADES & CURIOSIDADES & CURIOSIDADES & CURIOSIDADES \\
\hline Seção & $\begin{array}{l}\text { GENTE E CULTURA } \\
\text { BRASILEIRA }\end{array}$ & $\begin{array}{l}\text { GENTE E CULTURA } \\
\text { BRASILEIRA }\end{array}$ & $\begin{array}{l}\text { GENTE E } \\
\text { CULTURA } \\
\text { BRASILEIRA }\end{array}$ & $\begin{array}{l}\text { GENTE E } \\
\text { CULTURA } \\
\text { BRASILEIRA }\end{array}$ \\
\hline Seção & ENFOQUE & ENFOQUE & ENFOQUE & ENFOQUE \\
\hline Seção & PSIU! & PSIU! & PSIU! & PSIU! \\
\hline Seção & AMPLIE SEU & AMPLIE SEU & AMPLIE SEU & AMPLIE SEU \\
VOCABULÁRIO & VOCABULÁRIO & VOCABULÁRIO \\
\hline
\end{tabular}

Como vemos, neste Grupo ocorre uma mudança nas duas primeiras seções, que saem de uma perspectiva mais gramatical e passam a tratar de curiosidades em torno dos conteúdos.

As unidades dos Grupos 4 e 5 apresentam uma nova abordagem. A última seção das unidades não será mais nomeada como "História", mas sim como "Amplie seu vocabulário". Desse modo, nas seções pertencentes ao quarto grupo, são apresentados para o aluno gêneros textuais mais formais, voltado ao mercado de trabalho mais especifico, como atas, memorandos, ofícios, gêneros estes classificados pelos autores de LD como "Correspondências". Ademais, observa-se que mais uma vez não são apresentadas atividades a partir das quais o professor possa solicitar como produto da leitura, ficando, assim, a critério do docente a melhor forma de abordagem. Já no que se refere às seções da quinta unidade, os textos são referentes a turismo, o que de certo modo retoma o visto no início do livro, de forma mais detalhada.

Não poderíamos deixar de mencionar que mesmo que as apresentações das autoras para cada grupo sejam retiradas de outra edição, ocorre esta repetição de temáticas e estruturações, mencionadas pelas próprias autoras na edição mais recente, na qual fazem referência de manter o formato devido ao sucesso obtido pelo livro.

Após conhecermos a parte estrutural do livro, partiremos agora para a nossa análise propriamente dita. Para tanto, consideramos quatro atividades, nas quais buscaremos associar os critérios avaliativos do Exame Celpe-Bras, mas para além disto, detectar a presença da abordagem comunicativa no livro didático. Vale ressaltar que neste processo, não estamos buscando uma generalização em torno do material analisado, mas sim, refletir sobre de que forma, como docente, poderemos potencializar o aproveitamento deste material.

Para além desta associação e como forma de atender a esta reflexão entorno do material, buscaremos também imaginar possíveis situações de uso sendo assim, daremos início com a explicação das nomenclaturas que adotamos, vejamos o Quadro 9 a seguir, 
Quadro 9- Classificação e seus respectivos critérios avaliativos

\begin{tabular}{|c|c|}
\hline CLASSIFICAÇÃO & CRITÉRIOS \\
\hline - Não CELPE & $\begin{array}{l}\text { Atividade que apresenta uma natureza Metalinguística, } \\
\text { voltadas para a classificação e identificação gramatical, } \\
\text { trabalhando fora da usualidade. }\end{array}$ \\
\hline - Quase CELPE & $\begin{array}{l}\text { Atividade que apresenta uma natureza Epilinguística, } \\
\text { mas que ainda apresente resquícios não usuais. }\end{array}$ \\
\hline - CELPE & $\begin{array}{l}\text { Atividade que tenha como ponto de partida o uso, } \\
\text { levando o aluno à reflexão da língua alvo, resultando na } \\
\text { produção de um gênero textual. }\end{array}$ \\
\hline
\end{tabular}

Fonte: a própria autora, 2019.

Sendo assim, não poderíamos deixar de ressaltar uma informação relevante, não utilizaremos atividades que tenham como ponto de partida o vídeo, pois, o LD não utiliza esta ferramenta como texto base de suas atividades, diferentemente do que ocorre com a prova Celpe-Bras.

A primeira atividade escolhida para a análise está localizada no Grupo 1, mais precisamente na Unidade I e na seção "Psiu!", ou seja, segundo a nossa classificação inicial, faz parte do que entendemos como o nível básico da língua, vejamos a atividade a seguir,

Atividade 1: Primeira atividade analisada

VAMOS CONHECER BENEDITA COSTA

REPÓRTER: Qual é o seu nome?

BENE: Benedita Costa

REP.: Prazer em conhecê-la.

BENE: O prazer é meu.

REP.: Você é estudante?

BENE: Não, sou atleta.

REP.: Profissional?

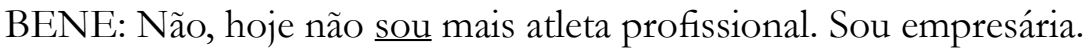

REP.: Quem $\underline{\text { são }}$ estas pessoas nestas fotos?

BENE: Esta sou eu e minha família. Aqui nós estamos no Ceará. Nós todos somos cearenses, de Fortaleza.

REP.: Seu pai também é empresário?

BENE: Não, meu pai é professor universitário e minha mãe é dona de casa.

REP: Quem é esta moça?

BENE: Carla, minha irmã. E ao lado dela está José, seu filho. Hoje ele está na França. Carla é psicóloga e hoje em dia nós duas estamos em São Paulo.

REP.: Como é o seu dia a dia?

BENE: Bem, pela manhã eu normalmente estou em casa e à tarde no escritório. Tenho sempre muitas coisas a fazer em casa: escrevo artigos para jornais, leio novidades sobre o atletismo, estudo inglês, faço ligações de negócios. À tarde tenho reuniões de trabalho. Normalmente chego em casa à noite. Minha irmã também trabalha muito. À noite estamos sempre muito cansadas.

\section{Leia o texto, assinale as alternativas corretas e corrija as incorretas:} CORRETA INCORRETA

1. Benedita é jogadora de squash. 
2. A família toda de Benedita é baiana.

3. O pai dela é professor universitário.

4. A irmã dela é tenista.

5. Carla está em São Paulo.

6. Pela manhã, Benedita está em casa.

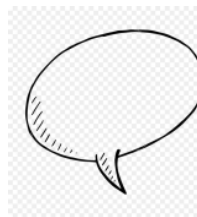

Traga uma foto de sua família e apresente-a a seu/ sua colega. Trabalhe em duplas. Utilize também os verbos introduzidos no texto acima. Tome nota das informações de seu/ sua colega e escreva uma redação sobre a família dele/a.

Fonte: Ponce, Burim e Florissi, 2017, p. 5.

Inicialmente, é possível observar que a construção da atividade se dá a partir do gênero entrevista, por seguinte, são feitas perguntas sobre o texto. O livro conta com um acervo online com os áudios para a realização das atividades, nesta atividade encontramos o áudio disponível, embora não pareça ser necessário ouvi-lo para a resolução das perguntas sobre o texto.

Classificamos estas atividades de duas formas, a primeira questão como uma questão Metalinguística (não Celpe), já no que se refere à segunda, ela está voltada para a abordagem Eplinguística (Quase-Celpe). As atividades acima, partem de uma conversa simulada, pois no áudio observamos que é uma conversa programada para o livro, e que mesmo partindo de um gênero, o foco é apenas a retirada de simples informações do texto.

Não podemos deixar de destacar, o que inclusive já foi falado anteriormente, que a atividade corresponde ao nível básico da língua, nível este que podemos associar às questões de noções e funções, que explicamos anteriormente, no capítulo da abordagem comunicativa. Sendo assim, podemos classificar, que se trata de uma questão que busca levar o aluno a detectar as noções da língua, ser capaz previamente de identificar as informações presentes no texto.

Além de apenas identificar, a atividade trabalha com duas das capacidades exigidas na prova, que são a Compreensão escrita e a oral, como também a Produção escrita e oral. Sendo assim, mesmo que dentro das limitações do nível básico, as noções de produção e compreensão são abordadas para que ocorra um aprofundamento nos grupos posteriores, que veremos se realmente ocorre. Não poderíamos deixar de comentar que a unidade tem como objetivo trabalhar os primeiros contatos do estrangeiro com o novo país e utiliza das cores para destacar um dos primeiros verbos estudados e que os estrangeiros mais apresentam dificuldades, que são os verbos "ser" e "estar", que durante toda a conversa/atividade é destacado pela cor verde (por nós adaptado com sublinhado e negrito).

Por fim, para que ocorra a potencialização desta atividade supomos que o professor deva ter como objetivo partir do texto para trabalhar as questões relacionadas à gramática, sendo assim, a utilização do gênero entrevista, que neste caso é apresentado em forma de diálogo, é o que os alunos mais tem contato, inclusive nos meios televisivos. Ainda nesta questão da potencialização, gostaríamos de reforçar que o professor, não necessariamente precisaria ficar preso apenas ao livro, mas partiria para outras questões interpretativas e de forma mais dialogada, o que inclusive, já seria um treino para a própria produção oral dos alunos. Como últimas considerações acerca desta atividade, observamos que não estão presentes os papéis sociais, que mais uma vez, ficaria como 
sugestão para o trabalho do professor em sala de aula, especialmente em níveis mais elevados, em que já se possa promover pequenas produções de texto ou de um gênero completo.

Passaremos agora para a segunda atividade escolhida, atividade que está presente no Grupo 2, na Unidade 8, mais especificamente na seção "Psiu!", sendo assim, atividade encontra-se direcionada ao nível Pré-intermediário da Língua Portuguesa. Vejamos a questão a seguir:

Atividade 2: Segunda atividade analisada

11. Você foi convidado para passar um fim de semana em algum lugar. Envie uma mensagem eletrônica agradecendo o convite e desculpando-se por não poder ir. Explique o motivo seguindo o modelo abaixo:

园 (1) $\quad \odot>{ }^{E} \triangle 10: 09$

$\rightarrow$ Antônio

Vendo agora

Querido Antônio,

Muito obrigado por convidar-

me a passar o fim de semana na

sua casa, em Gramado. 10:09

Sempre quis conhecer Gramado, mas tenhc

um trabalho para entregar na segunda-feira

por isso, infelizmente, não vai ser possivel

aceitar o seu convite. 10:09

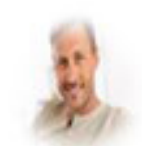

Numa próxima oportunidade, talvez.

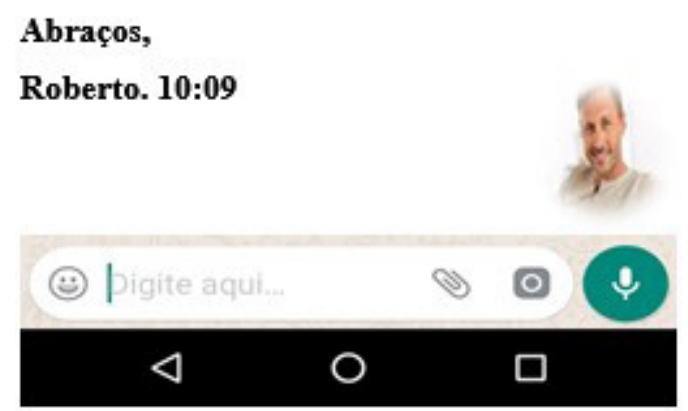

Fonte: Ponce, Burim e Florissi, 2017, p. 78 (adaptado).

Observa-se que o gênero escolhido para ser trabalhado nesta atividade é a mensagem de texto, algo que está próximo da realidade do estrangeiro/aluno. Contudo, diferentemente da atividade anterior, observamos que esta se dá diretamente em uma abordagem Epilinguística, construída a partir de uma situação real de uso.

Em comparação com a primeira atividade, observamos uma progressão na construção do enunciado, que mesmo tratando-se de um gênero mais informal, mesmo assim, sofre um acréscimo de uma finalidade e o meio de divulgação, nesta questão que classificamos como quase CELPE, a 
partir da construção do enunciado e do nível que consideramos que o aluo já possua, entendemos que o aluno, já seja capaz de refletir sobre estas questões. Associando aos critérios comunicativos, o aluno já seria capaz de trabalhar nesta questão as noções e as funções comunicativas, além disto, trabalharia a Compreensão escrita, como também a Produção escrita, que poderíamos associar, com a proposta das Tarefas 3 e 4 do Exame Celpe- Bras. Entretanto, propõe produções mais resumidas, como também, é direcionada para um nível que não recebe certificação dentro do Exame Celpe-Bras.

Como forma de potencialização da atividade, acreditamos que o professor poderá partir desta atividade, para trabalhar um gênero mais formal, como o e-mail, ou até mesmo a carta, pois, considerando a forma que este diálogo foi construído, poderíamos destacar fatores tais como, o Vocativo (Querido Antônio), o Corpo da mensagem, que foi inicialmente construída por um agradecimento, seguido de uma justificativa, por seguinte, uma Despedida (Numa próxima oportunidade, talvez. Abraços) e por fim a Assinatura (Roberto), sendo assim, de forma mais estrutural, até mesmo comparativa, que se daria através da apresentação de outros modelos, o professor começaria um trabalho de aprofundamento ainda maior, o que o próprio livro cobra posteriormente.

A terceira atividade, por sua vez, é composta por um texto e duas questões. Essa atividade encontra-se no Grupo 4, dentro da Unidade 14, na seção "Psiu!". Trata-se, então, de uma atividade direcionada ao Nível Intermediário Superior, segundo a nossa classificação. Vejamos:

Atividade 3: Quarta atividade analisada

Dinheiro é a razão para tanto empenho

Aproveitar os feriados prolongados para trabalhar- e bem mais- pode parecer loucura para muitas pessoas. Mas há quem tire proveito disso. A representante de atendimento Rosana Pessoa dos Santos, 32, é prova incontestável desse comportamento. No mercado de trabalho há 15 anos, ela diz que, se poder escolher, não emenda nenhum feriado. "Trabalho sempre, de manhã, de tarde, ou de noite. É só chamar que eu vou.” A razão para tanto empenho profissional é o dinheiro: "Quando não sou convocada para trabalhar aos domingos e feriados, acabo comprando as horas extras dos colegas". A pesar de trabalhar mais que o marido, Rosana diz que isto não atrapalha o relacionamento: "Ele é muito legal e já se adaptou ao meu jeito". Ela afirma que quando tem que trabalhar aos domingos e feriados, o café da manhã fica pronto mais cedo. "E no fim, meu marido acaba me levando ao trabalho ", afirma.

Fonte: Jornal Folha de São Paulo

1. Você é proprietário de uma loja em um grande Shopping Center no Rio Grande do Sul. É dezembro e, como todo ano, você precisa de reforço no seu grupo de vendedores. Imagine-se entrevistando Rosana. Trabalhe em pares: um de vocês é Rosana e o outro, o proprietário da loja. Façam um diálogo.

2. Você está desempregado e precisa arrumar dinheiro de qualquer maneira, mesmo que seja fazendo "bico", ou seja, um trabalho temporário. Veja os anúncios ao lado, escolha o que você gostaria de fazer e explique o porquê. Explique também por que não faria os outros trabalhos. 


\begin{tabular}{|l|l|}
\hline Garçom/ Garçonete & Entregadores \\
Universitários, masculino/ feminino, p/ trabalhar & Rapazes p/ entregar (150 vagas). Salário \\
em casa noturna. Comp. À Rua Sebastião Pereira & R\$1.200,00+ VR+ VT. Ligue 99900-0535- R\$ 4,49 \\
da Rocha, 359, Pinheiros, $2^{\text {a }}$ feira, a partir das 13h. & $\mathrm{p} / \mathrm{min}$. \\
SACOLEIRA & OP. TELEMARKETING \\
P/ venda de camisas finas, c/ ganhos & Masc. Editora. Sal. = com. CP 60.009 Cep 05096- \\
aproximados de R\$ 300,00 diários. Tratar F: 3955- & $970 \mathrm{SP}$ \\
0367 hc. Maria Helena/ João. & \\
\hline
\end{tabular}

Fonte: Ponce, Burim e Florissi, 2017, p. 133(adaptado).

A partir das atividades acima, observamos que ocorreu uma progressão na própria construção, as quais passaram a priorizar questões mais discursivas, passaram a ser atividades que em sua maioria leva os alunos a refletirem sobre o uso, o mais interessante desta atividade, é que a temática abordada é a mesma, empregos e a diferença se dá a partir do papel social que se assume.

Consideramos também mais uma progressão, pois a atividade deixa de ser mecanicista e passa a ser reflexiva, sendo assim, além de atender as questões esperadas para o Celpe-Bras, passa a ser um complemento, pois o aluno agora de forma quase simultânea passa a pensar sobre os papeis sociais, os enunciadores, interlocutores, meio de divulgação e o mais importante é apresentado um texto base, para nortear a conversa, por isso mesmo classificamos esta atividade como CELPE. Vale ressaltar, que nesta questão, diferentemente das anteriores, nos é apresentado um texto de uma situação real de uso, como podemos ver na presença da referência, o que é um ponto positivo, pois leva cada vez mais o aluno a proximidade da realidade.

Em síntese, a partir da nossa análise, inferimos que no que se refere ao ensino de Língua Portuguesa, tanto para nativos como para não nativos, as escolhas das atividades de acordo com os alunos e os gêneros são de suma importância, pois, assim como indicam os pressupostos da Abordagem Comunicativa, as atividades devem partir do uso, direcionando para reflexão e voltando (como produto, isto é, como gênero) para o uso. Logo, mesmo as atividades metalinguísticas, associadas ao conjunto, são relevantes para a aquisição de uma Língua, tanto para nativos, como para não nativos.

\section{REFERÊNCIAS}

ABRAHÃO, M. H. V. Algumas reflexões sobre a abordagem comunicativa, o pós-método e a prática docente. Revista EntreLínguas. v. 1, n. 1, jan./jun. 2015. Disponível em: http://bit.ly/2Nodsgy. Acesso 31 ago. 2019. ALMEIDA FILHO, J. C. P. Dimensões comunicativas no ensino de línguas. Campinas: Pontes, 2013.

ALMEIDA FILHO, J. C. P. O Ensino de Línguas no Brasil desde 1978. E Agora? Revista Brasileira de Linguística Aplicada, v. 1, n. 1, ALAB, 2001.

ANTHONY, E. Approach, Method and Technique. English Language Teaching, Oxford, n.17, 1963, p. 63-67. CELPEBRAS. Manual do Candidato. Disponível em: http://bit.ly/2Nni46L. Acesso em: 23 fev.2019. CELPEBRAS. Manual do aplicador. Disponível em: http://bit.ly/2QPvWJh. Acesso em: 10 fev. 2019. CELPEBRAS. Manual do examinando. Disponível em: http://bit.ly/35MZdsi. Acesso em: 03 fev. 2019. GERALDI, J. W. Portos de Passagem. 4. ed., São Paulo: Martins Fontes, 1997.

LARSEN-FREEMAN, D. Techniques and principles in language teaching. Oxford: Oxford University Press, 1986. Manual de Orientação para os coordenadores de Postos Aplicadores do Celpe-Bras. Disponível em: http:// bit.ly/35NxRC8. Acesso em: 30 de março de 2019.

MARCUSCHI, L. A. Produção textual, análise de gêneros e compreensão. São Paulo: Parábola Editorial, 2008. 
MARTINEZ, P. Didática de Língua Estrangeira. São Paulo: Parábola, 2009.

WILKINS, D. Notional Syllabyses. Oxford: Oxford University Press, 1976.

NEWMARK, L. How not to interfere with language learning. International Jounal of American Linguistics, v. 32, n. 1, part II, 1966.

NEWMARK, L.; REIBEL, D. A. Necessity and sufficiency in language learning. Cambridge: Cambridge University Press, 1968.

PONCE, M. H.; BURIM, S. A.; FLORISSI, S. Bem-vindo! a língua portuguesa no mundo da comunicação: português para estrangeiros (livro do professor). 4. ed. São Paulo: Special Book Services Livraria, 2009.

PONCE, M. H.; BURIM, S. A.; FLORISSI, S. Bem-vindo! a língua portuguesa no mundo da comunicação: português para estrangeiros. 9. ed., São Paulo: Special Book Services Livraria, 2017.

RICHARDS, J. C.; RODGERS, T. Approaches and Methods in Language Teaching. Cambridge: Cambridge University Press, 1986.

SCHENEUWLY, B.; DOLZ, J. Gêneros orais e escritos na escola. Campinas-SP: Mercado de Letras, 2004, p. 149-188. 